Original Article

\title{
BIOEQUIVALENCE STUDY OF AZELNIDIPINE 16 MG TABLET TO EVALUATE PHARMACOKINETIC PROFILE OF SINGLE DOSE IN HEALTHY, ADULT, HUMAN VOLUNTEERS UNDER FASTING CONDITION
}

\author{
DIBYA DAS ${ }^{1}$, DHIMAN HALDER ${ }^{2}$, ANIRBANDEEP BOSE ${ }^{3}$, CHIRANJIT SAHA ${ }^{3}$, HIMANGSHU SEKHAR MAJI ${ }^{*}$, TAPAN \\ KUMAR PAL ${ }^{2}$
}

${ }^{1}$ Department of Pharmaceutical Technology, JIS University, Kolkata 700109, 2Bioequivalence Study Centre, Jadavpur University, Kolkata 700032, ${ }^{3}$ TAAB Biostudy Services, Kolkata 700032

Email: hsmaji@jisuniversity.ac.in

Received: 06 Mar 2021, Revised and Accepted: 20 May 2021

ABSTRACT

Objective: The present study's objective is to conduct a comparative bioavailability study with a special emphasis on the test product's bioequivalence using a standard reference product as a comparator.

Methods: Before initiating the bioequivalence study, the plasma sample analysis method was developed and validated by using LC-MS/MS method. The entire study was conducted as a single-dose crossover randomized bioequivalence study with open-label, two treatment, two-period, and two sequences on 24 healthy volunteers under fasting condition. With proper informed consent process the oral dose of the Reference product (R) or Test product $(\mathrm{T})$ was administered on healthy volunteers at $0 \mathrm{~h}$ during each period of the study. After the drug's oral administration, a certain quantity of blood sample was collected, and the plasma sample was separated using a cold centrifuge. The plasma samples were analysed by using the validated LC-MS/MS method. The pharmacokinetic parameters, statistical data and ANOVA of the test and reference product were evaluated.

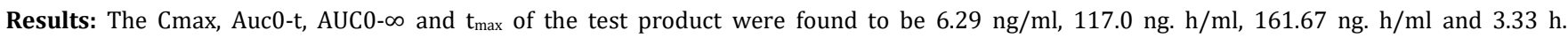
respectively. And the Cmax, Auc0-t, AUC0- $\infty$ and $\mathrm{t}_{\max }$ of reference product were found $6.59 \mathrm{ng} / \mathrm{ml}, 123.21 \mathrm{ng}$. h./ml, $172.20 \mathrm{ng}$. h/ml and $3.38 \mathrm{~h}$ respectively. Relative bioavailability was found $94.96 \%$. The overall results show that the $90 \%$ confidence intervals (Log-Transformed and Untransformed) for Cmax, AUC0-t and AUC0- $\infty$ for Azelnidipine were within the acceptable limit of 80\%-125\%.

Conclusion: The entire study's conclusion can be drawn as the test product was bioequivalence with the reference product's comparator.

Keywords: Bioequivalence study, Pharmacokinetic, Azelnidipine, Human volunteers, Fasting condition

(C) 2021 The Authors. Published by Innovare Academic Sciences Pvt Ltd. This is an open access article under the CC BY license (https://creativecommons.org/licenses/by/4.0/)

DOI: https://dx.doi.org/10.22159/ijap.2021v13i4.41331. Journal homepage: https://innovareacademics.in/journals/index.php/ijap

\section{INTRODUCTION}

Bioavailability and bioequivalence study are some of the most important criteria for the drug approval process from the perspective of the current regulatory status. Recent advancements in drug formulation technology provided us various novel formulations based on old generic drugs. But most of the formulation is found unsatisfactory in terms of bioavailability.

The drug's bioavailability should be monitored for the new formulation to understand the various pk parameters comparable or not.

Here we have conducted a thorough bioequivalence study of the new formulation of old generic drugs Azelnidipine.

Azelnidipine,(( \pm )-(3)-(1-diphenylmethylazetidin-3-yl)-5-isopropyl2-amino-1,4-dihydro-6-methyl-4-(3-nitrophenyl)-3,5-pyridinedicarboxylate; CS-905), is a third generation, long-acting dihydropyridine calcium antagonist [1].

The dihydropyridine calcium antagonists have two methyl groups [2] and two enantiomers (R-(-)-and S-(+)-enantiomers [3].

A novel drug, Azelnidipine, works by inhibiting both L and T-type calcium channels. Azelnidipine is lipophilic and highly vascular selective. The drug doesn't cause reflex tachycardia, and its antihypertensive actions appear to be the same as that of Nifedipine [4, 5].

Like Benidipne, Azelnidipne, too, has shown both high antiinflammatory and anti-oxidative properties. Azelnidipine has demonstrated the ability to inhibit inflammatory interleukins, cytokines and tumor necrosis factor, and a certain amount of free radical scavenging property. By virtue of this ability, Azelnidipine inhibits the inflammatory mediators and has shown to be effective in treating atherosclerosis, caused by damage of endothelial cells by all inflammatory interleukins, cytokines, tumor necrosis factors and monocytes, etc. [6, 7].

Under its anti-inflammatory properties, Azelnidipine has lower glomerular pressure (dilation of afferent and efferent arteries and arterioles) and reduces urinary albumin excretion [8-10].

Comparative pharmacokinetics needs to quantify the drug (Azelnidipine) in human plasma samples. Literature survey reveals that UPLC, HPLC and LC-MS/MS methods have been employed to determine Azelnidipine alone or in combination with other drugs. Some of these earlier reported studies were found to be tedious, time-consuming and less cost-effective. The plasma extraction technique used in the previous studies was also not found to be costeffective, and the total run time was found lengthy. Therefore, in the present study, efforts were made to develop and validate a bioanalytical method for simultaneous Azelnidipine estimation in human plasma by LC-MS/MS to analyze plasma samples obtained from the comparative pharmacokinetic studies on healthy human volunteers under the framework of bioequivalence study. Efforts were also made to use cost-effective and straightforward extraction techniques [11-13].

A pharmacokinetic study was conducted on Chinese volunteers using the LC-MS method. But the bioequivalence study was not conducted with all required parameters [14].

Further investigation finds many clinical studies were conducted on various groups of patients with a single or combination of Azelnidipine with other drugs. But pharmacokinetic studies of a single molecule with the bioequivalence study were not investigated with the detailed procedure. Few pharmacokinetic studies were traced with combination drugs. Instead of these, a single-molecule pharmacokinetic study with proper bioequivalence study according to standard regulatory 
guidelines was investigated by us only. So the manuscript will initiate a proper procedure to help other contract research organizations and pharmaceutical companies to perform bioequivalence study of Azelnidipine or another same type of drugs $[15,16]$.

\section{MATERIALS AND METHODS}

\section{Materials}

Test sample Azelnidipine Tablet contains Azelnidipine $16 \mathrm{mg}$ was manufactured and gifted by Akums Drugs And Pharmaceuticals, Plot No-19,20 and 21, Sec-6A, IIE, Ranipur, Haridwar (India). Reference Marketed samples of Calblock Tablet containing Azelnidipine $16 \mathrm{mg}$ manufactured by Daiichi-Sankyo Co. Ltd were purchased from the local market.

\section{Selection of volunteers}

\section{Selection of study population}

The general screening was conducted after the volunteers provided written consent on an IEC-approved 'Informed Consent for Screening' form. Demographic information such as sex, complete age, height and weight, BMI, diet, history of tobacco use, intake of abusive/recreational substances, alcohol intake, history of blood donation, and history of involvement in a drug research study. Health history, including related past surgical/medical history, food/drug/other allergy histories, family history, and past prescription history in the last $90 \mathrm{~d}$. recording vital signs such as blood pressure, pulse, temperature, and respiration, as well as general diagnosis, physical, and structural assessment, are all part of the medical test. Heart rate, rhythm, and relevant findings are assessed using a 12-lead ECG. X-ray of the chest (PA view); Parameter investigation in the laboratory, including Erythrocyte count, platelet count, hemoglobin, Hematocrit, leucocyte count, ESR, and differential leucocyte count are all part of a complete blood count. Grouping of blood, Hepatic profile-SGOT, SGPT, GGT, Alk. Biochemistry-blood sugar (fasting), triglycerides and cholesterol, Phosphatase and Bilirubin, Renal profile-creatinine, BUN, calcium, electrolytes such as sodium, potassium, and chlorides, and infectious diseases-HIV, HbsAg, and HCV, as well as a regular urine examination.

No clinically significant abnormalities in ECGs, chest X-ray (PA view) were reported in subjects who were included in the study. Additionally, serological tests (HIV, Hepatitis B and C, HCV) were negative. The volunteers with laboratory values within normal limits or clinically non-significant values were called one day before the study for study informed consent form presentation. Only those volunteers who signed the study informed consent form were checked in for the study on the day of check-in (one day before dosing).

All the volunteers were found negative for a urine test for drugs of abuse test and breath alcohol test [Cocaine, Amphetamines, Marijuana, Morphine, Barbiturates, and Benzodiazepine]. Hence all 24 fit and consenting volunteers fulfilling inclusion/exclusion criteria were enrolled in the study.

Volunteers were given the rank orders based on their reporting time to the facility on pre-study day. Based on their rank orders and compliance to the protocol requirements, subject numbers were allotted serially.

All inclusion and exclusion criteria for the volunteers were selected as per standard guidelines [17].

\section{Inclusion Criteria}

As per inclusion criteria, the volunteers were included based on different criteria like the healthy adult human male volunteers age within $18 \mathrm{y}$ to $45 \mathrm{y}$, weight not less than $50 \mathrm{~kg}$ and normal BMI within $18.50 \mathrm{~kg} / \mathrm{m}^{2}$ to $24.99 \mathrm{~kg} / \mathrm{m}^{2}$. Participate in the study willing to provide written Informed Consent. After that normal heart rate and blood pressure as measured after resting supine for $3 \mathrm{~min}$. Absence of disease markers of Syphilis, HIV 1 and HIV 2 and Hepatitis B. The volunteer must be a non-smoker. Volunteers' availability for the entire study duration, as well as their willingness to follow protocol guidelines, written informed consent is proof of this.

\section{Exclusion criteria}

As per exclusion criteria, the volunteers were excluded based on different criteria like History or presence of significant hepatic, immunologic, dermatologic, neurological, pulmonary, hematological, gastrointestinal, endocrine, cardiovascular, renal, psychiatric diseases, alcohol dependence and drug abuse during the past time. Found positive in breath alcohol test on the day of check-in. History of Asthma, urticarial, duodenal ulcer, peptic ulcer and Jaundice in the last 6 mo or disorder of bleeding.

One unit or $350 \mathrm{ml}$ blood loss within $56 \mathrm{~d}$ before the start of the study. Volunteers who had previously participated in a clinical study during the previous $90 \mathrm{~d}$ prior to the start of this study.

Refuse to fast for at least $10 \mathrm{~h}$ before and $4 \mathrm{~h}$ after drug administration. And refuse to refrain from drinking fluids for at least $1 \mathrm{~h}$ before and after taking the drug. Hypersensitivity to Azelnidipine and other related or un-related classes of drugs.

\section{Study design}

A randomized, open-label, two treatment, two-period, two sequences, single-dose, crossover bioequivalence study was conducted under fasting condition on 24 healthy, adult, human, male volunteers.

To evaluate the comparative Bioavailability study of a single dose of Azelnidipine Tablet containing Azelnidipine $16 \mathrm{mg}$ manufactured by an Akums Drugs And Pharmaceuticals, Plot No-19,20 and 21, Sec-6A, IIE, Ranipur, Haridwar (India) comparing with marketed samples of Calblock Tablet containing Azelnidipine $16 \mathrm{mg}$ manufactured by Daiichi-Sankyo Co., Ltd. India in healthy, adult, human volunteers under fasting condition.

Monitoring the safety and tolerability of a single dose of Azelnidipine Tablet $16 \mathrm{mg}$ when administered in healthy adult human volunteers.

\section{Diagnosis and foremost criteria for inclusion}

Healthy human volunteers within the age range of 18 to $45 \mathrm{y}$ with body mass index (BMI) of $18.50 \mathrm{~kg} / \mathrm{m}^{2}$ to $24.99 \mathrm{~kg} / \mathrm{m}^{2}$ having an absence of significant disease or laboratory evaluation or clinically significant laboratory values or medical history or physical examination during the screening and complying with inclusion and exclusion criteria were included.

\section{Criteria for evaluation}

\section{Efficacy}

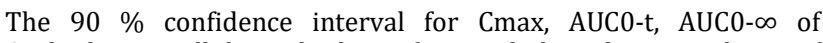
Azelnidipine will form the basis for concluding the equivalence of Azelnidipine in product $\mathrm{R}$ and $\mathrm{T}$. If the confidence intervals are entirely included in the range of $80 \%-125 \%$ for AUC0-t, AUC0- $\infty$, Cmax, log-transformed then the treatments will be claimed to be bioequivalence.

\section{Statistical methods}

The log-transformed pharmacokinetics (Cmax, AUC0-t and AUC0$\infty$.) were analyzed using an ANOVA model and calculated $90 \%$ confidence interval for the ratio of both the products averages (geometric means) of Cmax, AUC0-t and AUC0- $\infty$. Ratios of mean AUC0-t to mean AUC0- $\infty$ for test and reference are expressed in percentage, and power test is performed using SAS® version 9.1.3.

\section{Ethical conduct of the study}

\section{Independent ethics committee}

This protocol and corresponding informed consent form (ICF) to be used to obtain written informed consent of study subjects were reviewed by the HURIP Independent Bioethics Committee, Kolkata, West Bengal, India [CDSCO Registration No.: ECR/103/ Indt/WB/2013/RR-19]. And volunteers were not be enrolled on the study until the IEC approved the protocol and the ICF.

This study was conducted in accordance with the principles of the Declaration of Helsinki, 'ICH GCP', ICMR Guidelines, 'Indian GCP', and "Schedule Y" of the Indian Drugs and Cosmetics Act. 


\section{Written informed consent}

The Principal Investigator or designated study personnel informed the volunteers (vernacular language understandable by the subject) before initiating the study through an oral presentation regarding the purpose, procedures to be carried out, investigational products, potential hazards and rights of the study subjects. The volunteers were required to understand and sign the ICF prior to check-in for the study in the first period, and the signed ICF was filed in the respective study file.

\section{Overall study design and plan-description}

The study design was a randomized, open-label, two treatment, two periods, two sequences, single-dose, and crossover bioequivalence study under fasting conditions. It was using 24 healthy, adult, human, male volunteers.

\section{Treatments administered}

During each time, an oral dose of the Reference product (R) or Test product (T) was provided with $240 \mathrm{ml}$ of room temperature water at 0 $h$. The dosing end time was reported in raw data forms under the supervision of the Medical Officer and according to the randomization plan. In subsequent times, volunteers will undergo the alternative 'treatment,' ensuring that each participant has undergone both the 'treatments' evaluation and reference at the conclusion of the study.

\section{Method of assigning subjects to treatment groups}

According to the randomization schedule, the volunteers were assigned to the intake either test or reference product. The volunteer number was allocated as per the rank order of the subject's reporting time to the clinical facility.

\section{Drug concentration measurements}

The concentration of Azelnidipine was measured in plasma samples of the volunteers. The blood samples were collected (as per protocol) during the study at sampling hours at pre-dose and $0.50 \mathrm{~h}$, 1 h, 1.50 h, 2 h, 2.50 h, 3 h, 4 h, 6 h, 9 h, 12 h, 24 h, 48 h, 72 h and 96 $\mathrm{h}$ post-dose. Samples were collected through an indwelling cannula placed in a forearm vein. The pre-dose samples were collected within $1 \mathrm{~h}$ before drug dosing.

Blood samples were collected in a $5 \mathrm{ml} \mathrm{K} \mathrm{K}_{2}$ EDTA vial at the specified time. All the blood samples for a particular sample time point were centrifuged under refrigeration at $3500 \pm 20 \mathrm{rpm}$ and $4{ }^{\circ} \mathrm{C} \pm 1{ }^{\circ} \mathrm{C}$ for $10 \mathrm{~min}$. The resulting plasma was separated and stored in suitably labeled polypropylene tubes at $-20^{\circ} \mathrm{C} \pm 5^{\circ} \mathrm{C}$ for pending assay.

A total of 720 samples of Period-I and Period-II were transferred to the Bioanalytical section. The investigational products were administered in fasting conditions, and no food was served till $4 \mathrm{~h}$ post-dose. No fluid, except $240 \mathrm{ml}$ drinking water administered with the investigational products, was allowed from $1 \mathrm{~h}$ pre-dose and $2 \mathrm{~h}$ post-dose. The investigational products were administered to the volunteers while in the sitting posture. Volunteers were instructed to remain seated or be ambulatory for the first two hours following the drug administration. During this interval, under supervision, volunteers were permitted to leave the bed for brief periods, e. g. to use the washroom facilities. Then volunteers were allowed to engage only in normal activities while avoiding severe physical exertion.

\section{Restrictions}

Prior to dosing and during the study, all participants were advised to abstain from alcohol and xanthine-containing foods and beverages such as cold drinks, cigarettes, tobacco products, tea, coffee and chocolates for at least $48 \mathrm{~h}$. Before receiving any medicine, volunteers were also advised to refrain from eating an unusual diet for whatever cause, such as a low sodium diet, for $2 \mathrm{w}$ prior to receiving any medication and for the duration of their participation in the study.

\section{Prior and concomitant therapy}

Receipt of any other OTC drugs or prescription drugs within $2 \mathrm{w}$ prior to receiving the first dose of study medication or repeated use of drugs within the last $4 \mathrm{w}$ was an exclusion criterion. Further, the volunteers were not supposed to consume any medicines during the conduct of the study. Forty-four subjects who checked in the study confirmed that they did not consume any medication within the $2 \mathrm{w}$ of the start of the first period or during the study

\section{Bioanalytics and data processing}

A validated LC-MS/MS method was established for the estimation of Azelnidipine in human plasma. During the estimation of Azelnidipine in human plasma, quality control samples were distributed throughout each study sample batch $[18,19]$.

Samples from each subject were analyzed on the same standard curve. Samples with drug concentrations more significant than the upper limit of the validated range of the analysis would be diluted with the appropriate drug-free biological matrix and reanalyzed as per the method validation report.

The analysts concerned were blinded concerning the randomization code, and as a result, to the order of administration of the study medication.

\section{Method development and validation}

Accurate, sensitive, rapid, precise, and simple bioanalytical method development and validation were done of Azelnidipine in the human plasma using LC-ESI-MS/MS. The method was developed by gradient conditions using a $0.1 \%$ Formic Acid in Acetonitrile (Pump A) and Milli-Q water with $10 \mathrm{mmol}$ Ammonium acetate (Pump B) mobile phase with a flow rate of $0.5 \mathrm{ml} / \mathrm{min}$. The Analyte and IS (Metoprolol) were separated using a C18 Phenomenex $(50 \times 3 \mathrm{~mm}, 5 \mu)$ column. The chromatographic run time was $7.0 \mathrm{~min}$. The analyte and IS extracted from plasma by simple protein precipitation technique. The LOD and LLOQ were found to be $0.53125 \mathrm{ng} / \mathrm{ml}$ and $1.0625 \mathrm{ng} / \mathrm{ml}$, respectively. The calibration concentrations were $1.06 \mathrm{ng} / \mathrm{ml}, 2.13 \mathrm{ng} / \mathrm{ml}, 4.25$ $\mathrm{ng} / \mathrm{ml}, 8.5 \mathrm{ng} / \mathrm{ml}, 17 \mathrm{ng} / \mathrm{ml}, 34 \mathrm{ng} / \mathrm{ml}$, and $68 \mathrm{ng} / \mathrm{ml}$. The LQC, MQC and HQC were $3.19 \mathrm{ng} / \mathrm{ml}, 25.50 \mathrm{ng} / \mathrm{ml}, 51 \mathrm{ng} / \mathrm{ml}$ respectively. The validation parameters like inter-day, intra-day and stability studies were found within the range, as mentioned by USFDA [20] and EMA [21] guidelines, the results are given in table 2 and table 3 . The extraction recovery of the drug from plasma was high.

\section{Appropriateness of measurements}

The plasma samples of volunteers were analyzed by a validated LCMS/MS method. The limit of quantification of $1.06 \mathrm{ng} / \mathrm{ml}$ for Azelnidipine to quantify the analyte from the plasma samples collected up to $96 \mathrm{~h}$ after drug administration. The linearity range of $1.06 \mathrm{ng} / \mathrm{ml}$ to $68 \mathrm{ng} / \mathrm{ml}$ for Azelnidipine was enough to quantify the expected concentration range of Azelnidipine from volunteer plasma with the proposed dose of $16 \mathrm{mg}$ of Azelnidipine.

\section{Statistical and analytical plans}

\section{Following were the plans for statistical analysis}

We used SAS® system version 9.1.3 Analysis of Variance [ANOVA] to estimate pharmacokinetic parameters and its Statistical analysis for log-transformed pharmacokinetic parameters $\left[\mathrm{C}_{\max }, \mathrm{AUC}_{0-\mathrm{t}}\right.$ and $\mathrm{AUC}_{0}$ ळ] was performed. Ratio and $90 \%$ Confidence Interval for proportion and power for log-transformed pharmacokinetic parameters- $\mathrm{C}_{\max }$, $\mathrm{AUC}_{0-\mathrm{t}}$ and $\mathrm{AUC}_{0-\infty-\mathrm{was}}$ calculated. The confidence intervals are entirely included in the range of $80 \%-125 \%$ for AUC0-t, $\mathrm{AUC}_{0-\infty}$ and Cmax log-transformed then the treatments were claimed to be bioequivalence.

\section{RESULTS}

\section{Demographic and other baseline characteristics}

The mean \pm SD of age, height, weight and BMI values for regular healthy human volunteers recruited in the study and those analyzed demographic data is summarized in table 1.

\section{Interday and Intraday accuracy and precision}

The Interday and Intraday; accuracy and precision of Azelnidipine and IS were tested and the results in table 2 demonstrated that the evolved approach was reproducible and accurate. 
Table 1: Demographic data (24 Volunteers)

\begin{tabular}{|c|c|c|c|c|}
\hline & Age (Y) & Height $(\mathrm{cm})$ & Weight (kg) & BMI $\left(\mathrm{kg} / \mathrm{m}^{2}\right)$ \\
\hline mean \pm SD & $33.08 \pm 6.88$ & $164.08 \pm 5.79$ & $57.75 \pm 6.41$ & $21.43 \pm 1.85$ \\
\hline Maximum & 42 & 175 & 72 & 24.77 \\
\hline Minimum & 22 & 154 & 51 & 18.61 \\
\hline
\end{tabular}

$\mathrm{n}=24$ volunteers, mean \pm SD.

Table 2: Inter-day and Intraday accuracy and precision for Azelnidipine

\begin{tabular}{|c|c|c|c|c|c|c|c|c|c|}
\hline \multirow[b]{2}{*}{ QC Samples } & & \multicolumn{4}{|c|}{ Inter-day accuracy and precision (Between run) } & \multicolumn{4}{|c|}{ Intraday accuracy and precision (Within run) } \\
\hline & & Mean & SD & C. V. \% & Accuracy & Mean & SD & C. V. $\%$ & Accuracy \\
\hline LLOQ & $1.06 \mathrm{ng} / \mathrm{ml}$ & 1.102 & 0.098 & 8.853 & 103.718 & 1.022 & 0.060 & 5.887 & 96.188 \\
\hline LQC & $3.19 \mathrm{ng} / \mathrm{ml}$ & 3.188 & 0.294 & 9.237 & 100.016 & 3.384 & 0.112 & 3.308 & 106.165 \\
\hline MQC & $25.50 \mathrm{ng} / \mathrm{ml}$ & 25.147 & 2.062 & 8.200 & 98.617 & 24.746 & 0.798 & 3.225 & 97.043 \\
\hline HQC & $51.00 \mathrm{ng} / \mathrm{ml}$ & 49.272 & 4.662 & 9.461 & 96.612 & 46.874 & 2.023 & 4.315 & 91.910 \\
\hline
\end{tabular}

\section{Stability studies}

The various stability studies were conducted with freshly prepared QC concentrations of various concentrations, the results are given below table 3 .

\section{Summary data for subjects included in the final analysis}

The mean pharmacokinetic parameters estimated for both the reference and test formulations of Azelnidipine under fasting conditions are as follows in table 4:

Table 3: Stability of different QC standards in the different storing condition of Azelnidipine

\begin{tabular}{|c|c|c|c|c|c|}
\hline \multirow{3}{*}{ Stability studies } & \multicolumn{2}{|c|}{ QC samples (ng/ml) } & \multirow{2}{*}{$\begin{array}{l}\text { Mean } \\
2.93\end{array}$} & \multirow{2}{*}{$\begin{array}{l}\text { SD } \\
0.12\end{array}$} & \multirow{2}{*}{$\begin{array}{l}\text { C. V. \% } \\
3.99\end{array}$} \\
\hline & LQC & 3.19 & & & \\
\hline & MQC & 25.50 & 25.39 & 0.41 & 1.61 \\
\hline & HQC & 51.00 & 51.51 & 0.96 & 1.86 \\
\hline Autosampler Stability & LQC & 3.19 & 3.13 & 0.09 & 3.00 \\
\hline \multirow[t]{2}{*}{$(24 \mathrm{~h})$} & MQC & 25.50 & 26.29 & 0.48 & 1.84 \\
\hline & HQC & 51.00 & 52.28 & 1.13 & 2.16 \\
\hline Freeze-thaw Stability & LQC & 3.19 & 2.90 & 0.08 & 2.84 \\
\hline \multirow[t]{2}{*}{ (3 Cycles) } & MQC & 25.50 & 24.01 & 0.42 & 1.76 \\
\hline & HQC & 51.00 & 49.39 & 1.92 & 3.88 \\
\hline Short term Stability & LQC & 3.19 & 3.04 & 0.04 & 1.37 \\
\hline \multirow[t]{2}{*}{$(24 \mathrm{~h})$} & MQC & 25.50 & 24.07 & 0.36 & 1.49 \\
\hline & HQC & 51.00 & 45.28 & 1.05 & 2.33 \\
\hline \multirow{3}{*}{$\begin{array}{l}\text { Long term Stability } \\
(30 \mathrm{~d})\end{array}$} & LQC & 3.19 & 3.03 & 0.10 & 3.29 \\
\hline & MQC & 25.50 & 23.33 & 0.25 & 1.09 \\
\hline & HQC & 51.00 & 58.90 & 3.20 & 6.54 \\
\hline
\end{tabular}

Table 4: Pharmacokinetic parameters in 24 volunteers with the test and reference formulation

\begin{tabular}{|c|c|c|c|c|}
\hline \multirow{2}{*}{$\begin{array}{l}\text { Pharmacokinetic parameters } \\
\mathrm{C}_{\max }(\mathrm{ng} / \mathrm{ml})\end{array}$} & \multicolumn{2}{|c|}{ Reference formulation (R) } & \multicolumn{2}{|c|}{ Test formulation ( $\mathrm{T}$ ) } \\
\hline & Mean & 6.59 & Mean & 6.29 \\
\hline & $\pm \mathrm{SD}$ & 0.42 & $\pm \mathrm{SD}$ & 0.53 \\
\hline \multirow[t]{2}{*}{$t_{\max }(h)$} & Mean & 3.38 & Mean & 3.33 \\
\hline & $\pm \mathrm{SD}$ & 0.49 & $\pm \mathrm{SD}$ & 0.48 \\
\hline \multirow[t]{2}{*}{$\mathrm{AUC}_{0-\mathrm{t}}(\mathrm{ng} \cdot \mathrm{h} / \mathrm{ml})$} & Mean & 123.21 & Mean & 117.00 \\
\hline & $\pm \mathrm{SD}$ & 12.05 & $\pm \mathrm{SD}$ & 10.64 \\
\hline \multirow[t]{2}{*}{$\mathrm{AUC}_{0-\infty}$ (ng. h/ml) } & Mean & 172.20 & Mean & 161.67 \\
\hline & $\pm \mathrm{SD}$ & 27.36 & $\pm \mathrm{SD}$ & 14.70 \\
\hline \multirow[t]{2}{*}{$\mathrm{k}_{\mathrm{el}}\left(\mathrm{h}^{-1}\right)$} & Mean & 0.032 & Mean & 0.032 \\
\hline & $\pm \mathrm{SD}$ & 0.003 & $\pm \mathrm{SD}$ & 0.002 \\
\hline \multirow[t]{2}{*}{$t_{1 / 2}(h)$} & Mean & 22.02 & Mean & 21.61 \\
\hline & $\pm \mathrm{SD}$ & 3.15 & $\pm \mathrm{SD}$ & 1.40 \\
\hline Relative bioavailability (\%) & & $100 \%$ & & $94.96 \%$ \\
\hline
\end{tabular}

$\mathrm{n}=24$ volunteers, mean $\pm \mathrm{SD}$.

Table 5: $90 \%$ confidence interval

\begin{tabular}{ll}
\hline & Ln transformed \\
\hline $\mathrm{C}_{\max }$ & 0.95 to 0.99 \\
$\mathrm{AUC}_{0-\mathrm{t}}$ & 0.98 to 1.00 \\
$\mathrm{AUC}_{0-\infty}$ & 0.97 to 1.00 \\
\hline
\end{tabular}




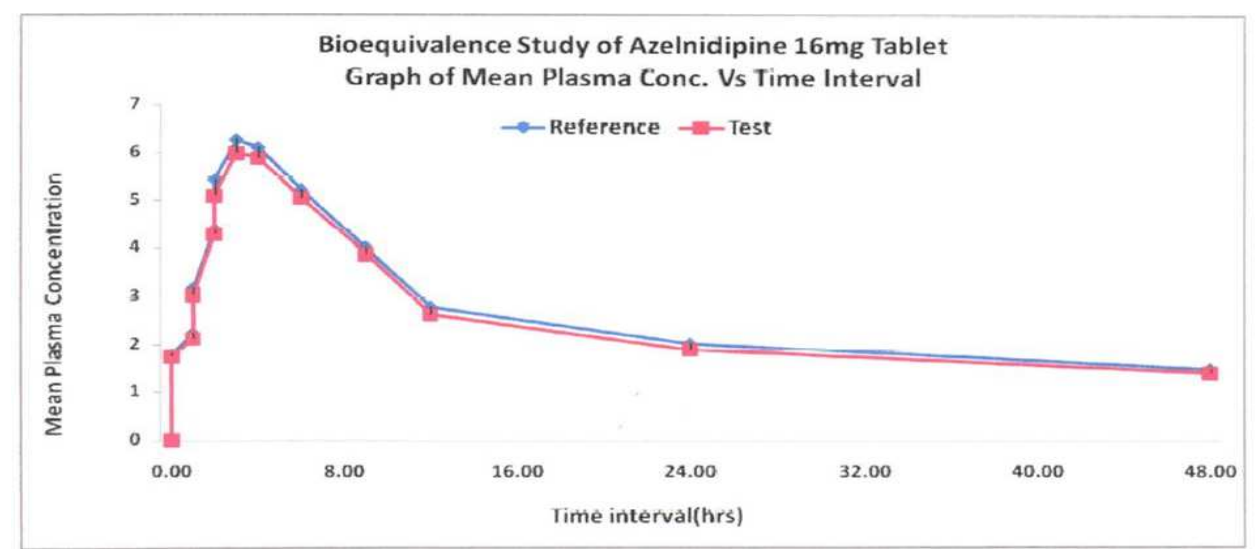

Fig. 1: Mean plasma concentration of test Vs reference preparation of azelnidipine $16 \mathrm{mg}$ tablet

\section{ANOVA summary $90 \%$}

Cmax: The ANOVA results for untransformed and log-transformed data of Cmax show that the parameters like Subject, Sequence, period and Treatment are not statistically significant at 5\%o level in both untransformed and log-transformed data.

The $90 \%$ confidence interval for the ratio (Test/Reference) of geometric means, based on the log-transformed data for Cmax, was $95.46 \%$ to $99.85 \%$ relative to Test preparation with Reference preparation.

AUC0-t: ANOVA results for untransformed and log-transformed data of AUC0-t show that the parameters like Subject, Sequence, period and Treatment are not statistically significant at 5\% level in both in transformed and log-transformed data.

The 90\% confidence interval for the ratio (Test/Reference) of geometric means, based on the log-transformed data for AUC0-t was found to be $97 \%$ to $100.17 \%$ relative to Test Preparation with Reference preparation.

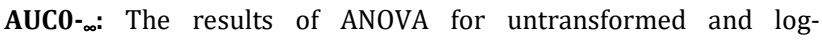
transformed data of AUC0- ${ }_{\infty}$ show that the parameters like Subject, Sequence, Period and Treatment are not statistically significant at $5 \%$ level in both untransformed and log-transformed data.

The 90\% confidence interval for the ratio (Test/Reference) of geometric means, based on the log-transformed data for AUC0- ${ }_{\infty}$ was found to be $97.86 \%$ to $100.06 \%$ relative to Test Preparation with Reference Preparation.

Tmax: The ANOVA results of Tmax data for the parameters like Subject, Sequence, Period and Treatment are not statistically significant at the $5 \%$ level.

Kel.: The results of ANOVA of Kel. data for the parameters like Subject, Sequence, Period and Treatment are not statistically significant at the $5 \%$ level.

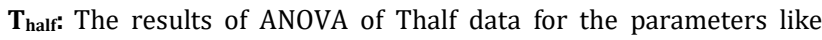
Subject. Sequence, Period and Treatment are not statistically significant at the $5 \%$ level.

The geometric mean has been calculated as the antilog (or exponential) of the least-square means of the log-transformed data.

Application of paired t-test that the Cmax (Untransformed data) for Test preparation and Reference preparation is not statistically significant at the $5 \%$ level and P-value: 0.070 . Both the preparations are similar effects on the body.

\section{DISCUSSION}

It was not possible to blind the appearance of the products so; it was an open-labeled study. The analysts were blind to the sequence of administration of the reference and test product to the individual subjects.

The order of receiving treatment was randomized to avoid bias in the allocation of sequence to the subjects.
There were two treatments: One product was the test product, while the innovator product as the reference product. The subjects served as their control, the study being a crossover.

There were two treatments, the trial design was two sequences, two periods. The effect of period and sequence on primary efficacy criteria were analyzed by ANOVA.

Healthy, adult, human participants were chosen to minimise variability in the control factors and biomedical experimentation, which could influence the assessment and comparison of primary efficacy factors.

The number of volunteers in the sample was calculated based on the variability of pharmacokinetic data available in the literature and was determined to be adequate to differentiate the bioavailability patterns of the products under study.

A total of 24 volunteers were enrolled in order to have the completed subject data set. All 24 volunteers enrolled completed the study. The plasma samples of the first 24 completed volunteers were analyzed for Azelnidipine concentration level and utilized the data for pharmacokinetic and statistical evaluations.

The pharmacokinetic parameters found in this analysis are consistent with those found in the published literature. Normal equations were used to determine bioequivalence. The $90 \%$ confidence intervals (LogTransformed) for Cmax, AUC0-t and AUC0- $\infty$ for Azelnidipine were within the usually acceptable limit 80\%-125\%.

Developed and validated plasma samples of analysis of Azelnidipine by using the technique of LC-ESI-MS. The method was applied to determine various pharmacokinetic parameters. The results show Peak plasma concentration in Chinese volunteers Cmax was found $8.66 \pm 1.15 \mathrm{ng} / \mathrm{ml}$. The LLOQ was $0.20 \mathrm{ng} / \mathrm{ml}$. We have a plasma concentration of Azelnidipine $29 \mathrm{ng} / \mathrm{ml}$. The LLOQ was found to be $1.06 \mathrm{ng} / \mathrm{ml}$. The entire result is comparable with that of the result found in the literature [14].

Determined Azelnidipine in human plasma by liquid chromatography-electrospray ionization-mass spectrometry. The LLOQ was $0.05 \mathrm{ng} / \mathrm{ml}$. The Cmax of the drug was found to be around $6.79 \mathrm{ng} / \mathrm{ml}$. In addition, some literature was also found in combination drug analysis for Azelnidipine. The results of those combination drugs were comparable with our results [22].

\section{CONCLUSION}

Both formulations are well-tolerated following a single dose administration of the investigational product. No clinical severe adverse events causing dropouts, hospitalization, disability, or death, of the subjects, were encountered. So, the test product is bioequivalence to the reference product of Azelnidipine $16 \mathrm{mg}$. No occurrence of adverse events during the study.

\section{ACKNOWLEDGEMENT}

The authors are thankful to M/S, TAAB Biostudy Services, Kolkata700032 and its entire team to conduct clinical studies in healthy human volunteers and provide the necessary instrumental facilities. 


\section{FUNDING}

This research work didn't receive any specific grant from any funding agencies or commercial sector.

\section{AUTHORS CONTRIBUTIONS}

All the authors have contributed equally.

\section{CONFLICT OF INTERESTS}

The authors declare that there is no conflict of interest.

\section{REFERENCES}

1. Azelnidipine. CS 905, Calblock, RS 9054. Drugs R D 2003;4:122-5.

2. Kawabata K, Urasaki Y. Simultaneous determination of azelnidipine and two metabolites in human plasma using liquid chromatography-tandem mass spectrometry. J Chromatogr B Anal Technol Biomed Life Sci 2006;844:45-52.

3. Kawabata K, Samata N, Urasaki Y. Enantioselective determination of azelnidipine in human plasma using liquid chromatography-tandem mass spectrometry. J Chromatogr B Anal Technol Biomed Life Sci 2007;852:389-97.

4. Tawaramoto K, Kaneto H, Hashiramoto M, Kawasaki F, Tatsumi F, Shimoda M, et al. Azelnidipine, but not amlodipine, reduces urinary albumin excretion and carotid atherosclerosis in subjects with type 2 diabetes: blood pressure control with olmesartan and azelnidipine in type 2 diabetes (BOAT2 study). Diabetol Metab Syndrome 2015;7:1-4.

5. Watanabe M, Hirano T, Okamoto S, Shiraishi S, Tomiguchi S, Uchino M. Azelnidipine, a long-acting calcium channel blocker, could control hypertension without decreasing cerebral blood flow in post-ischemic stroke patients. A 123 I-IMP SPECT follow-up study. Hypertens Res 2010;33:43.

6. Nada T, Nomura M, Koshiba K, Kawano T, Mikawa J, Ito S. Clinical study with azelnidipine in patients with essential hypertension. Arzneimittelforschung 2007;57:698-704.

7. Kiuchi S, Hisatake S, Kabuki T, Oka T, Dobashi S, Fujii T, et al. Azelnidipine is a useful medication for the treatment of heart failure preserved ejection fraction. Clin Exp Hypertension 2017;39:350-4.

8. Catterall WA, Perez Reyes E, Snutch TP, Striessnig J. International union of pharmacology. XLVIII. Nomenclature and structure-function relationships of voltage-gated calcium channels. Pharmacol Rev 2005;57:411-25.
9. Nakano K, Egashira K, Tada H. A third-generation, long-acting, dihydropyridine calcium antagonist, azelnidipine, attenuates stent associated neointimal formation in non-human primates. J Hypertens 2006;24:1881-9.

10. Nakamura T, Sugaya T, Kawagoe Y. Azelnidipine reduces urinary protein excretion and urinary liver-type fatty acid binding protein in patients with hypertensive chronic kidney disease. Am J Med Sci 2007;333:321-6.

11. Yamagishi T. Efficacy of azelnidipine on home blood pressure and pulse rate in patients with essential hypertension: comparison with amlodipine. Hypertens Res 2006;29:767-73.

12. Kario K, Sato Y, Shirayama M. Inhibitory effects of azelnidipine tablets on morning hypertension. Drugs R D 2013;13:63-73.

13. Sankyo Co. Calblock (azelnidipine) prescribing information Tokyo: Sankyo Co; 2003.

14. Zou JJ, Ji HJ, Zhou XH, Zhu YB, Fan HW, Xiao DW, et al. Determination of azelnidipine by LC-ESI-MS and its application to a pharmacokinetic study in healthy Chinese volunteers. Pharmazie 2008;63:568-70.

15. Oizumi K, Nishino H, Koike H, Sada T, Miyamoto M, Kimura T. Antihypertensive effects of CS-905, a novel dihydropyridine Ca++channel blocker. Japan J Pharmacol 1989;51:57-64.

16. Wellington K, Scott LJ. Azelnidipine. Drugs 2003;63:2613-24.

17. 'Guideline on the investigation of bioequivalence' (European Medicines Agency, London, CPMP/EWP/QWP/1401/98 Rev 1); 2010.

18. Halder D, Das S, Ghosh B, Biswas E, Roy S, Bose A, et al. An LCMS/MS based bioanalytical approach to resolve a pharmacokinetic investigation of acotiamide hydrochloride and its application to bioequivalence study. Int J Pharm Pharm Sci 2020;12:76-84.

19. Tijare LK, Rangari NT, Mahajan UN. A review on bioanalytical method development and validation. Asian J Pharm Clin Res 2016;9:6-10.

20. United States Food and Drug Administration. Guidance for Industry: Bioavailability and Bioequivalence Studies for orally Administered Drug Products; 2000.

21. The European Agency for the Evaluation of Medicinal Products EMA Committee for Proprietary Medicinal Products (CPMP) Note for guidance on the investigation of Bioavailability and Bioequivalence, London; 2001.

22. Ding L, Li L, Ma P. Determination of azelnidipine in human plasma by liquid chromatography-electrospray ionizationmass spectrometry. J Pharm Biomed Anal 2006;43:575-9. 